\title{
Kamu Kurumlarındaki EBYS Yazılımlarının TS 13298 Fonksiyonel Kriterlerine Uygunluğu
}

\section{Compliance of ERMS Software for TS 13298 Functional Requirements in Public Institutions}

\author{
Ceyhan Güler ${ }^{1}$ [)
}

'İstanbul Üniversitesi, Edebiyat Fakültesi, Bilgi ve Belge Yönetimi Bölümü, İstanbul, Türkiye

\section{ORCID: C.G. 0000-0003-0099-8168}

Sorumlu yazar/Corresponding author: Ceyhan Güler (Araş. Gör. Dr.), İstanbul Üniversitesi, Edebiyat Fakültesi, Bilgi ve Belge Yönetimi Bölümü, İstanbul, Türkiye E-posta: ceyhan.guler@istanbul.edu.tr

Başvuru/Submitted: 30.11 .2020 Revizyon Talebi/Revision Requested: 06.12.2020 Kabul/Accepted: 10.12 .2020 Online Yayı/Published Online: 31.12 .2020

Atıf/Citation: Güler, C. (2020). Kamu kurumlarındaki EBYS yazılımlarının TS 13298 fonksiyonel kriterlerine uygunluğu. Bilgi ve Belge Arasstırmaları Dergisi, 14, 85-104.

http://doi.org/10.26650/bba.2020.14.03

\section{ÖZ}

Kamu kurumlarında elektronik belge yönetim sistemlerine yönelik yazılım projelerinin uygulanmasında, proje teknik şartnamelerinin TS 13298'e uygun olarak hazırlanması, e-Devlet uygulamaları bağlamında önemlidir. Araştırmanın amacı, Kamu İhale Kurumunun Elektronik Kamu Alımları Platformu (EKAP) üzerinden erişim sağlanan 7 kamu kurumunun EBYS uygulama projelerine ait teknik şartnamelerini inceleyerek bu şartnamelerin, e-Devlet uygulamalarına uygunluğunu ortaya çıkarmaktır. Teknik şartnamelerde, fonksiyonel kriterlerin (FK) uygunluğunu değerlendiren, dosya tasnif planları (FK1), saklama planları (FK2), elektronik belgelerin kayıt işlemleri (FK3), elektronik belgelerin paylaşımı (FK4), EBYS kullanım özellikleri (FK5), erişim kontrolü ve güvenlik (FK6), sistem tasarım ve yönetimi (FK7) ve arșiv sisteminin güvenliği (FK8) olmak üzere sekiz başlık altında 70 isterin uygunluğu aranmaktadır. 2015-2018 yılları arası uygulamaları kapsayan bu çalışmada, doküman analizi yönteminden yararlanılmıştır. Araştırma sonucunda, teknik şartnamesi incelenen 7 kamu kurumunun genel olarak, FK1'e \%58.03, FK2'ye \%3.57, FK3'e \%71.42, FK4'e \%57.14, FK5'e \%92.20, FK6'ya $\% 65.17$, FK7'ye \%89.28 ve FK8'e \%25 oranında uygunluğu görülmüştür. Ayrıca, çıkan sonuçların 2015 yılı öncesi sonuçlarla karșılaștırmalı analizi yapılmıștır.

Anahtar kelimeler: Türkiye, kamu kurum ve kuruluşları, elektronik belge yönetim sistemi, teknik şartnameler, fonksiyonel kriterler

\section{ABSTRACT}

In case of implementation of software projects for electronic records management systems in public institutions, it is important in the context of e-Government applications to prepare the project technical specifications in accordance with TS 13298. The aim of the study is to examine the technical specifications of the ERMS implementation projects of 7 public institutions that are accessed via the Electronic Public Procurement Platform (EKAP) of the Public Procurement Authority and reveal the compliance of these specifications to e-Government applications. In technical specifications, in order to evaluate the compliance of functional criteria (FC), 70 requirements are sought under eight headings. Heading are file classification plans (FK1), retention schedules (FK2), capture of electronic records (FK3), sharing of electronic records (FK4), ERMS usage features (FK5), access control and security (FK6), system design and management (FK7) and the security of the archival system (FK8). The document analysis method was used in this study, which involved the years between 2015 and 2018. As a result of the research, 7 public institutions whose technical specifications were examined that provided the criteria at the following rates: $58.03 \%$ to $\mathrm{FK} 1,3.57 \%$ to $\mathrm{FK} 2,71.42 \%$ to $\mathrm{FK} 3,57.14 \%$ to FK4, $92.20 \%$ to FK5, and\% to FK6. $65.17,89.28 \%$ to FK7 and $25 \%$ to FK8. In addition, a comparative analysis was also made with the results of pre-2015.

Keywords: Turkey, public institutions and organizations, electronic records management system, technical specifications, functional criteria 


\section{EXTENDED ABSTRACT}

In case of implementation of software projects for electronic records management systems in public institutions, it is important in the context of e-Government applications to prepare the project technical specifications in accordance with TS 13298. The aim of the study is to examine the technical specifications of the ERMS implementation projects of 7 public institutions that are accessed via the Electronic Public Procurement Platform (EKAP) of the Public Procurement Authority and reveal the compliance of these specifications to e-Government applications. In technical specifications, in order to evaluate the compliance of functional criteria (FC), 70 requirements are sought under eight headings. Heading are file classification plans (FK1), retention schedules (FK2), capture of electronic records (FK3), sharing of electronic records (FK4), ERMS usage features (FK5), access control and security (FK6), system design and management (FK7) and the security of the archival system (FK8). The document analysis method was used in this study, which involved the years between 2015 and 2018. As a result of the research, 7 public institutions whose technical specifications were examined that provided the criteria at the following rates: $58.03 \%$ to FK1, 3.57\% to FK2, 71.42\% to FK3, 57.14\% to FK4, $92.20 \%$ to FK5, and\% to FK6. 65.17 , 89.28\% to FK7 and 25\% to FK8. In addition, a comparative analysis was also made with the results of pre-2015. Pre-2015, the rate of file classification plans providing requirements for TS 13298:2009 was 41.66\%. It is seen that this rate increased post-2015, but it is not at a high rate. Capture of electronic records was $30 \%$ pre-2015. It is seen that this rate has doubled post-2015. When we evaluate the rate of ERMS usage features, it was 55\% for pre-2015. Post-2015, it has been achieved a high rate of $92.20 \%$ compliance. Regarding access control and security, the rate pre-2015 was $55.55 \%$. It is understood that this rate has not increased much post-2015. Finally, when we look at the system design and management, the rate which was $47.91 \%$ pre-2015. It is increased to almost $90 \%$ post-2015. Since there are no criteria regarding retention plans, sharing electronic records and security of the archive system, no comparison was made between pre-2015 and post-2015. It is clear that the lack of electronic retention plans for pre-2015, or their low compliance for post-2015 will lead to major problems over time, and how the transformation needs will be determined with the aging of technology will pose a problem for institutions. Because, in records management and archival activities, archival appraisal of records is made according to retention plans. That is, it will be difficult to distinguish between records that need to be permanent stored and records that need to be destroyed. As a general result of this research, it is seen that the rate of compliance with ERMS software in public institutions increased according to TS 13298: 2015 functional criteria. However, it is understood that the requirements regarding records management and archival system were generally ignored pre-2015 and post-2015. The reason for this, raises the possibility that the technical specifications may have been prepared by IT staff or according to the areas of responsibility of different departments. Therefore, the archivist or records manager might not be involved in the preparation of the 
technical specification. It gives the impression that the archivist and records manager are not involved in the project, or they are not employed in the said institutions or ignored if they are employed. Another possibility is that the archivist or records manager has a lack of visibility in institutions. Another general evaluation result of the research is that some institutions that do not provide the criteria in high rate have tendered for the maintenance and support services of the ERMS software every year. The claim can be seen as the subject of another data based study. 


\section{GİRIŞ̧}

Günümüzün teknolojik imkânları, kamu kurumlarının dijital görünürlüklerini artırabilmelerine ve bu görünürlüklerinin etkin olarak kullanılabilmesine yardımcı olmaktadır. İnternet ve ağ teknolojilerinin özellikle 1990'lı yıllardan sonra gelişimi, hem bireylerin hem de kurumların muhatap oldukları alanlarda, söz konusu teknolojilerle karşılaşmalarını kaçınılmaz kılmıştır. Her kurum, hızlı ve ekonomik oluşu, şeffaf bir yapı sunması, görünürlüğü artırması gibi yararları dolayısıyla elektronik ortamdaki hizmetlerini daha etkin hale getirmeye çalışmaktadır. Özellikle kamu kurumları için bu yararların sağlanabilmesi bakımından elektronik ortamdaki iş akış süreçlerinin dinamik bir yapıda olması gerekmektedir. Ancak her kamu kurumu elektronik ortamdaki dinamik yapıyı sağlayabilecek teknik alt yapı ve yetkin uzman personele sahip değildir. Bunun tersi durumlarda kendi öz iş gücüyle alt yapı sağlama ve hizmetlerin elektronik ortamda sunulması mümkün olabilmektedir. Bunun dışında kamu kurumları, ağ teknolojilerinin kullanımı ve sundukları hizmetlerin, bu teknolojiler vasıtasıyla vatandaşa ulaştırılmasını dışarıdan hizmet alımıyla yapmaktadır. Kamu kurumları için hizmet alımının anlamı, Kamu İhale Kurumunun kuruluş amaciyla şekillenmektedir. Çünkü Kamu İhale Kurumu, hizmet alımları için 4734 sayılı Kamu İhale Kanunu (2002) ve 4735 sayılı Kamu İhale Sözleşmeleri Kanunu (2002) çerçevesinde hizmet alım süreçlerinin sağlıklı ve şeffaf bir şekilde yerine getirilmesini sağlamaya çalışmaktadır. Kamu İhale Kurumu, hizmet alımlarını gerçekleştirirken hem kendi görünürlük ve itibarını hem de verdiği hizmetler açısından diğer tüm kamu kurumlarının elektronik ortamdaki varlık ve görünürlüklerini yetkin ve etkin süreçlerle yönetmektedir.

Kamu kurumlarının sahip olduğu bilgi ve belgenin elektronik ortamda bir değer taşıması ve bu değerin birey ve kurumlarla paylaşılması ortak bir iletişim aracının kullanımını gerektirmektedir. Günümüzde kurumsal yazışmaların elektronik ortamda yürütülmesi, elektronik belge yönetim sistemlerinin (EBYS) kurumlarda tesis edilmesiyle mümkün görünmektedir. EBYS'lerin kurumlarda geliştirilmesi kurumların proje temelinde hizmet alımıyla gerçekleşmektedir. EBYS'lerin kurumlarda uygulanması ise kurumlar tarafından hazırlanan veya dışarıdan yine hizmet alımı yoluyla hazırlattırılan proje teknik şartnamelerinin, kurumların ihtiyaçlarına cevap verecek ve teknik bilgilerin ayrıntılı olarak ifade edilmesine yardımcı olabilecek dokümanlarla yapılmaktadır.

Hizmet alımının gerçekleşeceği kurum ve hizmetin kimden ve ne şekilde (hangi teknik kriterler isteniyorsa) yapılacağının takip edilebilmesi için, hizmet alımı ihalesi Kamu İhale Kurumu tarafından elektronik ortamdaki Elektronik Kamu Hizmetleri Alımı Platformu (EKAP) üzerinden yapılmaktadır. EKAP'ta elektronik olarak yayınlanan ve hizmet alımına ilişkin hazırlanan teknik şartnamenin, gerekli teknik ihtiyacın EBYS hizmet alımına yönelik ulusal ve uluslararası standartlar rehberliğinde yapılması istenmektedir. Türk Standartları (TS) 13298 Elektronik Belge ve Arşiv Yönetimi Standardı olarak bilinen ve kamu kurumlarında gerçekleşecek EBYS hizmet alımlarında, bu standarda uygun teknik kriterler belirlenmesi, 2008/16 sayılı Başbakanlık Genelgesi ile zorunludur. 
$\mathrm{Bu}$ çalışmanın amacı, EKAP üzerinden yayınlanan EBYS yazılım hizmet alımını gerçekleştiren kamu kurumlarına ilişkin teknik şartnamelerin, TS 13298 fonksiyonel kriterlerine uygunluğunun incelenmesidir. Ayrıca, 2015 yılı öncesini kapsayan, Güler (2018)'in ele aldığı, 12 kamu kurumunun teknik şartnamelerinin EBYS'ye uygunluğu verileri ile bu araştırmada ele alınan 7 kamu kurumu teknik şartnamesinin EBYS'ye uygunluk verileri de karşılaştırılmıştır. Bu karşılaştırmanın, TS 13298:2009 ile TS 13298:2015 olarak farklı revizyonlara göre standardın değerlendirmesini de sağlaması beklenmektedir. Bu çalışmada, ele alınan 7 kurumun fonksiyonel kriterlere uygunluğu, aşağıdaki araştırma sorularının doküman analiziyle incelenmesini gerekli kılmıştır.

Teknik şartnamelerdeki;

- Dosya tasnif planlarının, EBYS standardına uygunluk oranı nedir?

- Saklama planlarının, EBYS standardına uygunluk oranı nedir?

- Elektronik belgelerin kayıt işlemlerinin, EBYS standardına uygunluk oranı nedir?

- Elektronik belgelerin paylaşımının, EBYS standardına uygunluk oranı nedir?

- EBYS kullanım özelliklerinin, EBYS standardına uygunluk oranı nedir?

- Erişim kontrolü ve güvenlik isterlerinin, EBYS standardına uygunluk oranı nedir?

- Sistem tasarım ve yönetimi isterlerinin, EBYS standardına uygunluk oranı nedir?

- Arşiv sisteminin güvenliği isterlerinin, EBYS standardına uygunluk oranı nedir?

\section{Arka plan}

\section{Kamu Alımlarında Eşik Değerler Ve Doğrudan Temin}

4734 sayılı Kamu İhale Kanunu (2002, m. 18), idarelerce mal veya hizmet alımları ile yapım işlerinin ihalelerinde; açık ihale usulü, belli istekliler arasında ihale usulü ve pazarlık usulü olmak üzere üç usulden birinin uygulanmasını istemektedir. Söz konusu Kanun’un “Temel İlkeler" başlığı altında (2002, m. 5) "Bu Kanuna göre yapılacak ihalelerde açık ihale usulü ve belli istekliler arasında ihale usulü temel usullerdir. [...] Diğer ihale usulleri Kanunda belirtilen özel hallerde kullanılabilir" ifadeleri pazarlık usulünün özel hallerde kullanılabileceğini ifade etmektedir. İlgili Kanunun "Şartnameler” (12. m) başlı̆̆ı altında;

İhale konusu mal veya hizmet alımları ile yapım işlerinin her türlü özelliğini belirten idari ve teknik şartnamelerin idarelerce hazırlanması esastır. Ancak, mal veya hizmet alımları ile yapım işlerinin özelliği nedeniyle idarelerce hazırlanmasının mümkün 
olmadığının ihale yetkilisi tarafından onaylanması kaydıyla, teknik şartnameler bu Kanun hükümlerine göre hazırlattırılabilir

şeklinde ihale usullerine bakılmaksızın teknik şartnamelerin idarelerce hazırlanması veya hazırlatılması istenmiştir. Dolayısıyla bu araştırmadaki teknik şartnameler, ihale usulüne bakılmaksızın 4734 sayılı Kamu İhale Kanunu kapsamındaki ihaleleri ilgilendirmektedir. Bununla birlikte, büyükşehir belediyeleri sınırları içerisinde faaliyet gösteren idarelerin 67.613 Türk Lirası'na kadar; diğer belediye sınırları içerisinde faaliyet gösteren idarelerin ise 22.524 Türk Lirası'na kadar olan meblağlardaki mal, hizmet ve yapım işleri için “doğrudan temin” hakları vardır (Kamu İhale Kanunu, 2002, m. 22/d; Kamu İhale Tebliği, 2018). Söz konusu eşikler, 4734 sayılı Kamu İhale Kanununda belirtilen eşik değerlerin ve parasal limitlerin, Türkiye İstatistik Kurumu tarafından açıklanan 2018 ve 2019 yılı Aralık aylarında Yurt İçi Üretici Fiyat Endeksi (Yİ-ÜFE) yıllık değişim oranında 2018 yılı için \%33,64 (Kamu İhale Tebliği, 2019), 2019 yılı için \% 7,36 (Kamu İhale Tebliği, 2020) arttırılarak güncellenmiştir. Dolayısıyla, tek kalemde yapılabilecek mal, hizmet ve yapım işlerinin ilgili idare tarafından makul şekilde başka adlar altında, eşik değerleri aşmayan ve küçük kalemlere bölünen alım işini hayata geçirmeleri mümkündür. Bu durum, bir idarenin ihtiyaç duyduğu mal, hizmet ve yapım işleri için -eşik değerler korunmak kaydıyla- ihaleye çıkma zorunluluğunun olmadığını, eşik değerleri aşmayan “doğrudan temin”ler ile ilgili teknik şartnamelerin EKAP'ta yayınlanmayacağını ve “doğrudan temin” yoluyla küçük parçalar halinde EBYS alımlarının yapılabileceğini göstermektedir.

Doğrudan temin usulü, ihale usullerinin temel ilkelerinden sayılan kurallara uymaksızın, ilan yapılmadan, teminat alınmadan, ihale komisyonu kurma ve anılan Kanun'da belirtilen yeterlik kriterlerini taşıma zorunluluğu aranmaksızın, ihale yetkilisi tarafından görevlendirilen kişi ya da kişiler tarafından piyasada fiyat araştırması yapılarak temin edilen bir satın alma usulü olarak ifade edilerek ihale sürecinden tamamen ayrılmıştır. (Atuğ ve Taytak, 2018, s. 109).

Dolayısıyla, kamu kurumlarında EBYS yazılımlarının sağlanmasında, doğrudan temin yönteminin kullanılıyor olması nedeniyle, EKAP'ta ihale bilgileri görünmeyen; ancak EBYS yazılımı edinen birçok kurumun olabileceğini söylemek mümkündür.

\section{Kamu İhale Kurumu Ve Hizmet Alımlarına İlişkin Süreç Bileşenleri}

Kamu İhale Kurumunun, kuruluşunun yanı sıra görev ve yetkileri de 4734 Sayılı Kamu İhale Kanunu çerçevesinde düzenlenmiştir. Kanuna göre, Kamu İhale Kanununun amac1, kamusal hukuk çerçevesinde alımları gerçekleştiren ya da devlet kontrolünde alım yapabilen kurum ve kuruluşlar için alım işlerini belirli bir yöntemle yapmaktır. Kamu İhale Kanunu'nun ihalelerle ilgili şartnamelerin ayrıntılarının belirtilmesi ise 4735 sayılı Kamu İhale Sözleşmeleri 
Kanunu'nda yer bulmaktadır (Aksoy ve Şimşek, 2010, s. 35). 4734 sayılı Kamu İhale Kanunu (2002)'na göre teknik şartnameler ile ilgili bazı bilgiler şu şekildedir:

İhale konusu mal veya hizmet alımları ile yapım işlerinin her türlü özelliğini belirten idari ve teknik şartnamelerin idarelerce hazırlanması esastır. Ancak, mal veya hizmet alımları ile yapım işlerinin özelliği nedeniyle idarelerce hazırlanmasının mümkün olmadığının ihale yetkilisi tarafından onaylanması kaydıyla, teknik şartnameler bu Kanun hükümlerine göre hazırlattırılabilir. İhale konusu mal veya hizmet alımları ile yapım işlerinin teknik kriterlerine ihale dokümanının bir parçası olan teknik şartnamelerde yer verilir. Belirlenecek teknik kriterler, verimliliği ve fonksiyonelliği sağlamaya yönelik olacak, rekabeti engelleyici hususlar içermeyecek ve bütün istekliler için fırsat eşitliği sağlayacaktır.

Kanun maddesinde de ifade edildiği üzere, teknik şartnameler ihale dokümanlarının önemli bir parçasını oluşturmaktadır. Yine bu kanunda teknik dokümanlarının verimliliği, fonksiyonelliği ve firsat eşitliği sağlayacağı belirtilmiş, ayrıca idarelerin bu noktada sorumlulukları vurgulanmıştır. $\mathrm{Bu}$ sorumluluğu yerine getirmek, kamu alımlarında teknik şartnameleri etkin bir şekilde kullanmak anlamına gelmektedir.

Aynı kanunda, teknik şartnamelerin dünya çapında geçerliliği olan standartlara uygunluğunun yanı sıra ilgili olduğu mal veya hizmet alımını daha iyi ifade edecek şu açıklamalara da yer verilmektedir. "Teknik şartnamelerde, varsa ulusal ve/veya uluslararası teknik standartlara uygunluğu sağlamaya yönelik düzenlemeler de yapılır. Bu şartnamelerde teknik özelliklere ve tanımlamalara yer verilir (Kamu İhale Kanunu, 2002). Bu bağlamda, bu araştırmanın EKAP üzerinden yapılacak hizmet EBYS alımlarının TS 13298 standardına uygunluğunun tartışılması, söz konusu kanunda istenen şartın sağlanması ve 2008/16 sayılı Başbakanlık Genelgesi ile uygunluk açısından da önemlidir. Ayrıca Kamu İhale Kanunu'nda belirtilen teknik kriterlerin karşılanması, verimliliği ve fonksiyonelliği sağlamaya yönelik olarak istenmektedir. Bu durum, teknik şartnamelerin, Türk Standartları Enstitüsünün EBYS yazılımları için fonksiyonel isterlere göre değerlendirilmesini de anlamlı kılmaktadır.

\section{Yöntem ve Sinırlılıklar}

$\mathrm{Bu}$ araştırmada doküman analizi yönteminden yararlanılmıştır. Araştırmanın verileri, TS 13298'in fonksiyonel isterlerine göre aşağıda yer alan 7 kurumun Elektronik Kamu Alımları Platformu'nda (EKAP) yayınladığı teknik şartnamelerinden elde edilmiştir. Teknik şartnamelerin EBYS çerçevesinde uygunluğu aşağıdaki başlıklara bağlı olarak yapılmıştır. Bu başlıklar, TS 13298: 2015'teki dosya tasnif planları, saklama planları, elektronik belgelerin kayıt işlemleri, elektronik belgelerin paylaşımı, EBYS kullanım özellikleri, erişim kontrolü ve güvenlik, sistem tasarımı ve yönetimi ve son olarak da arşiv sisteminin güvenliği gibi 
fonksiyonel kriterlerdir. Fonksiyonel kriterler, Türk Standartlar Enstitüsünün TS 13298'in yazılım ürünlerine yapılacak olan fonksiyonel testlerdeki kriterlerdir. Analiz edilen teknik şartnameler, bu başlıkların kapsadığ 70 kritere göre değerlendirilmiştir. Bu çalışmada ele alınan, 7 kurum aşağıda verilmiştir. Bunlar;

- Afyonkarahisar Sağlık Bilimleri Üniversitesi (2018) EBYS yazılımı teknik şartnamesi (İhale Kayıt No: 2018/613757),

- Darıca Belediyesi (2017) süreç bazlı web tabanlı yönetim bilgi sistemi yazılım modülleri ve elektronik belge yönetim sistemi hizmet alımı işi teknik şartnamesi (İhale Kayıt No: 2017/396242),

- İzmir Büyükşehir Belediyesi ESHOT Genel Müdürlüğü (2017) elektronik belge yönetim sistemi (EBYS) teknik şartnamesi (İhale Kayıt No: 2017/216516),

- Konya Gıda ve Tarım Üniversitesi (2017) elektronik belge yönetim sistemi şartnamesi (İhale Kayıt No: y.),

- Sağlık A.Ş. (2017) elektronik belge yönetim sistemi (EBYS) alımı işi teknik şartnamesi (İhale Kayıt No: 2017/571190),

- Şanlıurfa Büyükşehir Belediyesi (2016) elektronik belge yönetim sistemi (EBYS) teknik şartnamesi (İhale Kayıt No: 2016/19671),

- Türkiye İhracat ve Kredi Bankası A.Ş. (Türk Eximbank) (2018) elektronik belge yönetim sistemi (EBYS) uygulaması lisans, geliştirme, danışmanlık, kurulum, bakım ve destek hizmeti alımı teknik şartnamesi (İhale Kayıt No: 2018/15724) dir.

Belirtilen 7 kurum dışında, EKAP'tan erişilebilen bir diğer teknik şartname de Kadıköy Belediyesine ait EBYS teknik şartnamesidir. İhale iptalinden dolayı, söz konusu teknik şartname değerlendirmeye alınmamıştır. Çalışmanın sınırlılıkları da şu şekildedir:

- EKAP'ta, EBYS ihale teknik şartname dokümanlarının büyük bir oranda yayımlanmaması, bu çalışmanın sınırlı sayıda (7 kurum) kalmasına neden olmuştur.

- Birçok kamu kurumunun, EBYS projesine yönelik ihaleye çıkılmasına rağmen bu kurumların teknik şartnamesine EKAP üzerinden erişim sağlanamamıştır. Muhtemelen ilgili kanuna göre eşik değerlerin aşılmaması nedeniyle EKAP’ta yayımlanmamıştır.

- Çalışmaya dâhil edilen, 7 kurumun, her ne kadar EBYS'nin bir parçası olarak görülse de fiziksel arşivlerin düzenlenmesine veya dijitalleştirmeye/sayısallaştırmaya yönelik hazırlamış oldukları proje teknik şartnameleri, çalışmaya dâhil edilmemiştir. EBYS'ye yönelik proje teknik şartnameleri değerlendirilmiştir. 
- İhale teknik şartnamelerinin, TS 13298: 2015'teki başlık ve alt kriterlere göre sıralanmaması ve kullanılan ifadelerin farklılık arz etmesi gibi nedenler, şartnamelerin TS 13298 ile karşılaştırılmasında bazı sapmalara sebep olmuştur.

- Bu çalışmanın verileri, 2015-2018 yılları arası yapılan EBYS yazılım projelerine ait dokümanları kapsamaktadır.

- 2019 ve 2020 yıllarında yapılmış elektronik belge yönetim sistemine ilişkin ihale dokümanlarına, ihale dokümanın EKAP'ta mevcut olmamasından dolayı erişim sağlanamamıştır.

\section{Literatür Değerlendirmesi}

EBYS yazılım projelerine ilişkin EKAP'ta yayımlanmış teknik şartnamelerin TS 13298 standardına uygunluğu için yararlanılan araştırmalardan biri, teknik şartnamelerdeki gözlemlenen sorunların dile getirildiği ve üç farklı kamu kurumunun hazırlamış oldukları teknik şartnamelerin, teknik ve idari açıdan karşılaştırıldığı çalışmadır (Çiçek, 2013).

Elektronik belge yönetimi uygulamalarında karşılaşılan sorunların analizi ve çözüm önerilerinin sunulduğu bir diğer çalışmada, Kalkınma Bakanlığı (artık ilga edilen) örneği üzerinden yürütülen araştırmadır (Umut ve Külcü, 2014). Araştırmada, teknik şartnamelerin TS 13298'e uygunluğu dışında teknik şartname kaynaklı bazı sorunlar ele alınmıştır. Arşiv ve belge yönetim sistemiyle ilgili personel gruplarına yapılan anket sonuçlarına göre, bu sorunların, grubun yarıdan fazlasının kararsız ve olumsuz görüş bildirdikleri bazı hususların teknik şartnameye bağlı sorunlar olduğu tespit edilmiştir. Bunlar; sistem üzerinde belgelerin düzenli olarak ayıklanmaması, sorunlara dönük teknik desteğin yetersizliği, sistemin kullanımı ve özelliklerine yönelik eğitim faaliyetlerinin yetersizliği, sistemin e-posta sistemleri ile entegre çalışmaması ve sistemde çevrimiçi yardım hizmetinin yetersizliğidir (Umut ve Külcü, 2014, s. 120). Bu araştırmayla doğrudan ilişkisi olmayan bir diğer makalede, elektronik belge yönetimi uygulamalarında başarıyı etkileyen risk unsurları değerlendirilmiştir (Yalçınkaya, 2015). $\mathrm{Bu}$ çalışmada teknik şartnamelere ilişkin olarak, kamu kurum ve kuruluşlarının edindikleri uygulamaların asgari olarak referans modeline dayandırılarak hazırlandığını, TSE tarafından yapılan denetimler neticesinde 40 kurumun standarda uygun iş süreçleri geliştirdikleri ifade edilmiştir (Yalçınkaya, 2015).

EBYS yazılım projelerine ilişkin EKAP'ta yayımlanmış teknik şartnamelerin TS 13298 standardına uygunluğu, Güler (2018)'in 12 kamu kurumunu, TS 13298: 2009'a göre incelemesi ve teknik şartnamelerde gözlemlenen ve yaşanan problemleri ele aldığ 1 çalışmasında görülmektedir. 


\section{Bulgular ve Yorum}

\section{Teknik Şartnamelerin EBYS'ye Uygunluğu (2015 Yılı Öncesi)}

2015 y1lı öncesi teknik şartnameler, dosya tasnif planları, planın oluşturulması, tanımlanması ve yönetilmesi olmak üzere 3 kriter bağlamında karşılaştırılmış̧ı. Söz konusu 12 kamu kurumunun dosya tasnif planlarındaki kriterlere uygunluğu $\% 41,66$ olarak belirlenmişti.

Elektronik belgelerin kayıt işlemleri, ilgili kriterlere 12 kamu kurumunun uygunluğu genel özellikler, dokümanların belgeye dönüştürülmesi ve ilişkilendirme, belge türleri, taşıma, kopyalama - silme ve referans kodlarının verilmesi olarak 6 kriter altında incelenmiş̧ti. İncelemeye göre, belirtilen kamu kurumlarının elektronik belgelerin kayıt işlemleriyle uygunluğu \%30 olarak saptanmıştı. EBYS kullanım özellikleri ile ilgili kriter uygunluk tablosuna göre, 12 kamu kurumunun uygunluğu, genel özellikler, arama, görüntüleme, yazdırma ve raporlama olarak 5 kriterde incelenmişti. Buna göre kurumların EBYS kullanım özellikleri kriterine uygunluğu \%55'ti. 12 kamu kurumunun erişim kontrolü ve güvenlik ile ilgili kriterlere uygunluğu, sisteme giriş, erişim hakları, kullanıcı profilleri, kullanıcı rolleri, kullanıcı grupları, kayıtlara erişim haklarının atanması ve uygulanması, üretim sorumluluğu, bilgi edinme hakkı ve özel hayatın korunması ve denetim olarak 9 kriterle incelenmişti. Kurumların erişim kontrolü ve güvenlik kriterlerine uygunluğu $\% 55,55$ 'ti. 12 kamu kurumunun sistem tasarım ve yönetimi ile ilgili kriterlere uygunluğu, sistem bütünlüğü ve güvenirlik, kullanım kolaylığı, performans ölçeklenebilirlik ve verilerin depolanması olarak 4 kriter altında incelenmişti. Buna göre değerlendirmeye alınan kurumların sistem tasarım ve yönetimi kriterine uygunluğu $\% 47,91$ olarak görülmüştü. Doküman yönetimi ile ilgili kriterlere 12 kamu kurumunun uygunluğu, girdi yönetimi, tanımlama ve indeksleme, depolama/yedekleme ve çıktı yönetimi olarak 4 kriterle incelenmişti. Kurumların doküman yönetimi kriterine uygunluğu \%56,25’ti. Elektronik olmayan sistemlerle uyumluluk ile ilgili kriterlere göre 12 kamu kurumunun uygunluğu, fiziksel dosya ve belgelerin sisteme dâhil edilmesi, tanımlama ve erişim kontrolü-kullanım olarak 3 kriterle incelenmişti. Kurumların elektronik olmayan sistemlerle uyumluluk kriterine uygunluğu \%69,44'tü. Tüm Kurumların EBYS'ye uygunluğu teknik şartnamesi değerlendirilen 12 kurumun elektronik belge yönetim sistemine ilişkin teknik şartname, toplam 7 temel başlık altında incelenmiş ve 12 kamu kurumunun, tüm kriterlere uygunluk yüzdesi \%54,4 olarak ölçülmüştü (Güler, 2018, s. 7-13).

Sonuçlara bakıldığında kurumların toplam kriterlerin yarısından fazlasını sağladığı görülmüştü. Bu sonuçlar, TS 13298'in 2009 yılında yayınlandığı kriterler bağlamında değerlendirilmişti. Bu nedenle, söz konusu sonuçlar, 2015 yılı öncesi kamu kurumlarındaki elektronik belge yönetimi uygulamalarının, TS 13298: 2009 uygunluğunu yansıtmaktadır. 2015 yılında güncellenen standart, Türk Standartları Enstitüsünün Bilişim İhtisas Kurulu'na bağlı TK01 Bilişim Teknolojileri Teknik Komitesi’nce TS 13298: 2009'un revizyonu olarak 
hazırlanmış ve TSE Teknik Kurulu'nun 23 Ekim 2015 tarihli toplantısında kabul edilerek yayımına karar verilmiştir. Bu standardın daha önce yayımlanmış bulunan baskıları da geçersiz sayılmıştır (TSE, 2015). Güncellenen TS 13298: 2015 bir önceki revizyonuna ilave olarak kurumlar arası belge paylaşımı, kayıtlı elektronik postaların yönetimi, elektronik yazışma paketi ve elektronik arşivlerin yönetimi başta olmak üzere bazı yenilikler getirmektedir. Standardın bu revizyonunda Elektronik Arşivleme Sistemi Referans Modelinin (ELAS/RM) adı altında yeni bir bölüm eklenmiştir. Bu bölüm (TSE, 2015):

- Elektronik belgelerin üretildikleri dönemdeki hukuki varlığının korunabilmesi,

- Sürekli saklanacak elektronik belgelerin kesintisiz olarak erişilebilirliğinin sağlanması için gerekli tedbirlerin alınması,

- Elektronik belgelerin üretildiği bilgi sistemi platformundan bağımsız olarak erişilebilir olması için, gerekli sistem gereksinimlerini, elektronik arşivleme sistemleri uygulamalarında bulunması, gerekli temel arşivcilik fonksiyonlarını ve elektronik arşivde yer alacak belgelerin sisteme transfer, düzenleme, tanımlama ve kullanımı gibi fonksiyonlara uygun üstveri modelini tanımlaması üzerine şekillenmiştir.

\section{Elektronik belge yönetim sistemlerinde teknik şartnamelerin TS 13298: 2015'e uygunluğu (2015 yılı sonrası)}

2015 yılı sonrası için 7 kurumun teknik şartnamesi incelenmiştir. Bunlar; Türkiye İhracat ve Kredi Bankası A.Ş. (Türk Eximbank)'e ait elektronik belge yönetim sistemi (EBYS) uygulaması lisans, geliştirme, danışmanlık, kurulum, bakım ve destek hizmeti alımı teknik şartnamesi (2018), Afyonkarahisar Sağlık Bilimleri Üniversitesi EBYS yazılımı teknik şartnamesi (2018), Darıca Belediyesi (Kocaeli) süreç bazlı web tabanlı yönetim bilgi sistemi yazılım modülleri ve elektronik belge yönetim sistemi hizmet alımı işi teknik şartnamesi (2017), İzmir Büyükşehir Belediyesi ESHOT Genel Müdürlüğü elektronik belge yönetim sistemi (EBYS) teknik şartnamesi (2017), Konya Gıda ve Tarım Üniversitesi elektronik belge yönetim sistemi şartnamesi (2017), Sağlık A.Ş. elektronik belge yönetim sistemi (EBYS) alımı işi teknik şartnamesi (2017), Şanlıurfa Büyükşehir Belediyesi elektronik belge yönetim sistemi (EBYS) teknik şartnamesi (2016)'dir. Üç farklı yıla ve farklı kurumlara ait teknik şartnamelerdeki isterler, TS 13298'in fonksiyonel kriterlerine göre aşağıdaki başlıklarda değerlendirilmiştir. 
Tablo 1. Dosya tasnif planları (DTP) (FK1)

\begin{tabular}{|c|c|c|c|c|c|c|}
\hline Kurumlar & $\begin{array}{c}\text { DTP } \\
\text { oluşturulması } \\
\text { (4 ister) }\end{array}$ & $\begin{array}{c}\text { DTP } \\
\text { elemanlarının } \\
\text { tanımlanması } \\
(5 \text { ister })\end{array}$ & $\begin{array}{l}\text { DTP'nin } \\
\text { yönetilmesi } \\
\text { (7 ister) }\end{array}$ & $\begin{array}{l}\text { Toplam } \\
\text { (16 } \\
\text { ister) }\end{array}$ & Oran & $\begin{array}{l}\text { Tüm } \\
\text { Kurumların } \\
\text { Oranı }\end{array}$ \\
\hline $\begin{array}{l}\text { Afyonkarahisar } \\
\text { Sağllk Bilimleri } \\
\text { Üniversitesi }\end{array}$ & 2 & 2 & 6 & 10 & $\% 62$ & \multirow{7}{*}{$\% 58,03$} \\
\hline Darıca Belediyesi & 4 & 3 & 6 & 13 & $\% 81$ & \\
\hline $\begin{array}{l}\text { İzmir Büyükşehir } \\
\text { Belediyesi ESHOT } \\
\text { Genel Müdürlüğ̈̈ }\end{array}$ & 3 & 3 & 1 & 7 & $\% 43$ & \\
\hline $\begin{array}{l}\text { Konya Gida ve Tarım } \\
\text { Üniversitesi }\end{array}$ & 2 & 2 & 6 & 10 & $\% 62$ & \\
\hline Sağlık A.Ş. & 3 & 3 & 1 & 7 & $\% 43$ & \\
\hline $\begin{array}{l}\text { Şanlıurfa Büyükşehir } \\
\text { Belediyesi }\end{array}$ & 3 & 3 & 1 & 7 & $\% 43$ & \\
\hline $\begin{array}{l}\text { Türkiye İhracat ve } \\
\text { Kredi Bankası A.Ş. } \\
\text { (Türk Eximbank) }\end{array}$ & 4 & 2 & 5 & 11 & $\% 68$ & \\
\hline
\end{tabular}

Dosya tasnif planları, tabloda görüldüğü üzere, dosya tasnif planı oluşturulması, elemanlarının belirlenmesi ve yönetilmesi olmak üzere 16 isterde incelenmiştir. Kurumların isterlere uygunluk oran1 \%58,03 olarak görülmektedir. 2015 öncesi incelenen tüm kurumlarda oran \%41,66 idi. 2015 öncesi ve sonrası incelenen kurum sayıları farklı olsa da, 2015 y1lı sonrası kurumların isterleri sağlamaya çalıştığı anlaşılmaktadır. 2015 öncesi birçok kurumda, dosya tasnif planlarına yönelik hiçbir isterin sağlanmadığı görülmüştü.

Tablo 2. Saklama planları (FK2)

\begin{tabular}{|l|c|c|c|c|l|}
\hline Kurumlar & $\begin{array}{l}\text { Genel } \\
\text { (2 ister) }\end{array}$ & $\begin{array}{l}\text { Saklama süreleri } \\
\text { (2 ister) }\end{array}$ & $\begin{array}{l}\text { Toplam } \\
\text { (4 ister) }\end{array}$ & Oran & $\begin{array}{l}\text { Tüm Kurumların } \\
\text { Oranı }\end{array}$ \\
\hline $\begin{array}{l}\text { Afyonkarahisar Sağlık Bilimleri } \\
\text { Üniversitesi }\end{array}$ & 0 & 0 & 0 & $\% 0$ & \\
\hline Darıca Belediyesi & 1 & 0 & 1 & $\% 25$ \\
\hline $\begin{array}{l}\text { İzmir Büyükşehir Belediyesi } \\
\text { ESHOT Genel Müdürlüğü }\end{array}$ & 0 & 0 & 0 & $\% 0$ & \\
\hline Konya Gıda ve Tarım Üniversitesi & 0 & 0 & 0 & $\% 0$ & \\
\hline Sağlık A.Ş. & 0 & 0 & 0 & $\% 0$ & \\
\hline Şanlıurfa Büyükşehir Belediyesi & 0 & 0 & 0 & $\% 0$ & \\
\hline $\begin{array}{l}\text { Türkiye İhracat ve Kredi Bankası } \\
\text { A.Ş. (Türk Eximbank) }\end{array}$ & 0 & 0 & 0 & $\% 0$ & \\
\hline
\end{tabular}


Saklama planları, genel ve saklama süreleri olmak üzere 4 isterde sunulmuştur. Kurumların elektronik belgelerin saklanmasına ilişkin kriterleri, \%3,57 oranda karşıladığı görülmektedir. 2015 yılı öncesi incelenen kurumlarda saklama planlarıyla ilgili uygunluk aranmamıştır. Bunun nedeni, standardın 2009 yılı versiyonunda buna yönelik isterlerin yer almamasıdır. Ancak, elektronik ortamda saklama planlarının olmayışı veya çok az oranda uygunluk taşıması, zamanla büyük problemlere yol açacağı, teknoloji eskimesiyle dönüşüm ihtiyaçlarının neye göre belirleneceğinin kurumlar açısından problem teşkil edeceği aşikârdır. Çünkü, belge yönetimi ve arşiv faaliyetlerinde, belgelerin arşivsel değerlendirilmesi, değerlendirme sonucunda süresiz saklanılması gereken ve imha edilecek malzemenin birbirinden ayrılması, sistem çalışabilirliği ve sürekliliği üzerinde önemli bir etkiye sahiptir. Fiziksel belgelere kıyasla elektronik belgelerin saklanılması, maliyet açısından uygun gibi görünse de teknolojik uyumluluk açısından problem oluşturabilmektedir.

Tablo 3. Elektronik belgelerin kayıt işlemleri (FK3)

\begin{tabular}{|c|c|c|c|c|c|c|c|}
\hline Kurumlar & $\begin{array}{c}\text { Genel } \\
\text { Özellikler } \\
\text { (6 ister) }\end{array}$ & $\begin{array}{l}\text { Belge } \\
\text { türleri } \\
\quad(1 \\
\text { ister })\end{array}$ & $\begin{array}{c}\text { Elektronik } \\
\text { postaların } \\
\text { yönetimi } \\
\text { (2 ister) }\end{array}$ & $\begin{array}{c}\text { Taşıma, } \\
\text { kopyalama } \\
\text { ve silme } \\
\text { (1 ister) }\end{array}$ & $\begin{array}{c}\text { Toplam } \\
\text { (10 } \\
\text { ister) }\end{array}$ & Oran & $\begin{array}{c}\text { Tüm } \\
\text { Kurumların } \\
\text { Oranı }\end{array}$ \\
\hline $\begin{array}{l}\text { Afyonkarahisar } \\
\text { Sağlık Bilimleri } \\
\text { Üniversitesi }\end{array}$ & 6 & 0 & 2 & 1 & 9 & $\% 90$ & \multirow{7}{*}{$\% 71,42$} \\
\hline Darıca Belediyesi & 6 & 1 & 2 & 1 & 10 & $\% 100$ & \\
\hline $\begin{array}{l}\text { İzmir Büyükşehir } \\
\text { Belediyesi ESHOT } \\
\text { Genel Müdürlügü̈ }\end{array}$ & 3 & 0 & 2 & 1 & 6 & $\% 60$ & \\
\hline $\begin{array}{l}\text { Konya Gıda ve } \\
\text { Tarım Üniversitesi }\end{array}$ & 6 & 0 & 2 & 1 & 9 & $\% 90$ & \\
\hline Sağlık A.Ş. & 3 & 0 & 2 & 1 & 6 & $\% 60$ & \\
\hline $\begin{array}{l}\text { Şanlıurfa } \\
\text { Büyükşehir } \\
\text { Belediyesi }\end{array}$ & 3 & 0 & 2 & 1 & 6 & $\% 60$ & \\
\hline $\begin{array}{l}\text { Türkiye İhracat ve } \\
\text { Kredi Bankası A.Ş. } \\
\text { (Türk Eximbank) }\end{array}$ & 6 & 0 & 2 & 1 & 9 & $\% 60$ & \\
\hline
\end{tabular}

Elektronik belgelerin kayıt işlemleri, toplamda 10 ister kapsamında değerlendirilmektedir. Elektronik belgelerin, genel özellikleri, elektronik postaların yönetimi, taşıma-kopyalamasilme gibi işlemlerin, kurumlar tarafından \%71,42 oranında sağlandığı görülmektedir. 2015 yılı öncesi kurumların başarısı, \%30 oranındaydı. Sayıca daha fazla kurumun incelendiği 2015 öncesi kurumların başarı oranına göre, 2015 sonrası için iki katından fazla oranda uygunluk sağlanmıştır. Kurumların genel olarak kayıt işlemlerinde problem yaşamadıkları söylenebilir. 
Tablo 4. Elektronik belgelerin paylaşımı (FK4)

\begin{tabular}{|c|c|c|c|c|}
\hline Kurumlar & $\begin{array}{l}\text { Kayitlı elektronik } \\
\text { posta (5 ister) }\end{array}$ & $\begin{array}{l}\text { Toplam } \\
\text { (5 ister) }\end{array}$ & Oran & $\begin{array}{c}\text { Tüm } \\
\text { Kurumların } \\
\text { Oranı }\end{array}$ \\
\hline $\begin{array}{l}\text { Afyonkarahisar Sağlık Bilimleri } \\
\text { Üniversitesi }\end{array}$ & 3 & 3 & $\% 60$ & \multirow{7}{*}{$\% 57,14$} \\
\hline Darıca Belediyesi & 5 & 5 & $\% 100$ & \\
\hline $\begin{array}{l}\text { İzmir Büyükşehir Belediyesi ESHOT } \\
\text { Genel Müdürlüğü }\end{array}$ & 2 & 2 & $\% 40$ & \\
\hline Konya Gıda ve Tarım Üniversitesi & 3 & 3 & $\% 60$ & \\
\hline Sağlık A.Ş. & 2 & 2 & $\% 40$ & \\
\hline Şanlıurfa Büyükşehir Belediyesi & 2 & 2 & $\% 40$ & \\
\hline $\begin{array}{l}\text { Türkiye İhracat ve Kredi Bankası A.Ş. } \\
\text { (Türk Eximbank) }\end{array}$ & 3 & 3 & $\% 60$ & \\
\hline
\end{tabular}

Elektronik belgelerin paylaşımına ilişkin 5 istere göre uygunluk aranmıştır. Kayıtlı elektronik postanın \%57,14 oranında sağlanmaya çalışıldığı görülmektedir. ${ }^{1} 2015$ yılı öncesi elektronik belgelerin paylaşımına ilişkin isterlerin söz konusu olmaması nedeniyle karşılaştırma yapılamamıştır.

Tablo 5. EBYS kullanım özellikleri (FK5)

\begin{tabular}{|c|c|c|c|c|c|c|c|}
\hline Kurumlar & $\begin{array}{l}\text { Kullanım } \\
\text {-Genel } \\
\text { kurallar } \\
\text { (2 ister) }\end{array}$ & $\begin{array}{l}\text { Arama } \\
(3 \text { ister) }\end{array}$ & $\begin{array}{l}\text { Yazdırma } \\
\text { ( } 2 \text { ister) }\end{array}$ & $\begin{array}{l}\text { Raporlama } \\
\text { (4 ister) }\end{array}$ & $\begin{array}{l}\text { Toplam } \\
\text { (11 } \\
\text { ister) }\end{array}$ & $\begin{array}{l}\text { Yüzde } \\
\% 100\end{array}$ & $\begin{array}{c}\text { Tüm } \\
\text { Kurumların } \\
\text { Oranı }\end{array}$ \\
\hline $\begin{array}{l}\text { Afyonkarahisar } \\
\text { Sağlık Bilimleri } \\
\text { Üniversitesi }\end{array}$ & 2 & 3 & 2 & 4 & 11 & $\% 100$ & \multirow{7}{*}{$\% 92,20$} \\
\hline Darıca Belediyesi & 2 & 3 & 2 & 4 & 11 & $\% 100$ & \\
\hline $\begin{array}{l}\text { İzmir Büyükşehir } \\
\text { Belediyesi ESHOT } \\
\text { Genel Müdürlüğ̈ü }\end{array}$ & 2 & 3 & 2 & 2 & 9 & $\% 81$ & \\
\hline $\begin{array}{l}\text { Konya Gida ve } \\
\text { Tarım Üniversitesi }\end{array}$ & 2 & 3 & 2 & 4 & 11 & $\% 100$ & \\
\hline Sağlık A.Ş. & 2 & 3 & 2 & 2 & 9 & $\% 81$ & \\
\hline $\begin{array}{l}\text { Şanlıurfa Büyükşehir } \\
\text { Belediyesi }\end{array}$ & 2 & 3 & 2 & 2 & 9 & $\% 81$ & \\
\hline $\begin{array}{l}\text { Türkiye İhracat ve } \\
\text { Kredi Bankası A.SS. } \\
\text { (Türk Eximbank) }\end{array}$ & 2 & 3 & 2 & 4 & 11 & $\% 100$ & \\
\hline
\end{tabular}

1 Güncellenen TS 13298: 2015 bir önceki revizyonuna ilave olarak kurumlar arası belge paylaşımı, kayıtlı elektronik postaların yönetimi, elektronik yazışma paketi ve elektronik arşivlerin yönetimi başta olmak üzere bazı yenilikler getirmektedir (TSE, 2018). 
EBYS kullanım özelliklerine ilişkin toplam 11 isterin uygunluğu \%92,20'dir. Oldukça yüksek olan bu oranın, EBYS temel isterleri olmasından dolayı söz konusu oranın gerektiği gibi olduğunu göstermektedir. 2015 öncesiyle karşılaştırıldığında \%55 oranından, \%92,20 oranına çıkmış olması, EBYS yazılımlarının gün geçtikçe uygunluklarının arttığına işaret etmektedir. Kullanım isterleri, kullanımı sık olan arama, yazdırma, raporlama gibi isterleri kapsadığı için bu oranın \%100 oranında uygunluk sağlaması beklenmektedir.

Tablo 6. Erișim kontrolü ve güvenlik (FK6)

\begin{tabular}{|c|c|c|c|c|c|c|c|c|c|}
\hline Kurumlar & $\begin{array}{c}\text { Sisteme } \\
\text { Giriş } \\
\text { (2 ister) }\end{array}$ & $\begin{array}{l}\text { Erişim } \\
\text { Hakları } \\
\text { (4 ister) }\end{array}$ & $\begin{array}{c}\text { Kullanıcı } \\
\text { profilleri } \\
(2 \text { ister })\end{array}$ & $\begin{array}{c}\text { Kullanicı } \\
\text { rolleri } \\
\text { ( } 2 \text { ister) }\end{array}$ & $\begin{array}{c}\text { Kullanıcı } \\
\text { grupları } \\
\text { (4 ister) }\end{array}$ & $\begin{array}{c}\text { Günlük } \\
\text { dosyaların } \\
\text { oluşturulması } \\
\text { (2 ister) }\end{array}$ & $\begin{array}{l}\text { Toplam } \\
\qquad(16 \\
\text { ister })\end{array}$ & $\begin{array}{c}\text { Yüzdelik } \\
\text { Oran }\end{array}$ & $\begin{array}{c}\text { Tüm } \\
\text { Kurumların } \\
\text { Oranı }\end{array}$ \\
\hline $\begin{array}{l}\text { Afyonkarahisar } \\
\text { Sağlık Bilimleri } \\
\text { Üniversitesi }\end{array}$ & 1 & 3 & 2 & 1 & 3 & 2 & 12 & $\% 75$ & \multirow{7}{*}{$\% 65,17$} \\
\hline $\begin{array}{l}\text { Darica } \\
\text { Belediyesi }\end{array}$ & 2 & 3 & 2 & 1 & 3 & 2 & 13 & $\% 81,25$ & \\
\hline $\begin{array}{l}\text { İzmir } \\
\text { Büyükşehir } \\
\text { Belediyesi } \\
\text { ESHOT Genel } \\
\text { Müdürlüğü }\end{array}$ & 2 & 1 & 1 & 1 & 1 & 2 & 8 & $\% 50$ & \\
\hline $\begin{array}{l}\text { Konya Gida } \\
\text { ve Tarım } \\
\text { Üniversitesi }\end{array}$ & 1 & 3 & 2 & 1 & 3 & 2 & 12 & $\% 75$ & \\
\hline Sağlık A.Ş. & 2 & 1 & 1 & 1 & 1 & 2 & 8 & $\% 50$ & \\
\hline $\begin{array}{l}\text { Şanlıurfa } \\
\text { Büyükşehir } \\
\text { Belediyesi }\end{array}$ & 2 & 1 & 1 & 1 & 1 & 2 & 8 & $\% 50$ & \\
\hline $\begin{array}{l}\text { Türkiye } \\
\text { İhracat ve } \\
\text { Kredi Bankası } \\
\text { A.Ş. (Türk } \\
\text { Eximbank) }\end{array}$ & 1 & 3 & 2 & 1 & 3 & 2 & 12 & $\% 75$ & \\
\hline
\end{tabular}

Erişim kontrolü ve güvenlik, toplamda 16 ister ile uygunluğu aranmıştır. Kurumların bu uygunluğu \%65,17 oranında sağladıkları görülmektedir. 2015 öncesi uygunlukla karşılaştırıldığında \%55,55 oranından, \%65,17 oranına çıkmıştır. Günümüzde bilgi güvenliğine çok daha fazla önem verilmesi gerekmektedir. Kişisel Verilerin Korunması Kanunu’nun yürürlüğe girmesiyle, kurumların sahip olduğu kurumsal ve bireysel bilgilerin erişimi ve güvenliği konusunda ek tedbirlerin alınması istenmektedir. Nitekim kanunda, kişisel verilerin güvenli bir şekilde saklanması ile hukuka aykırı olarak işlenmesi ve erişilmesinin önlenmesi için alınmış teknik ve idari tedbirler açıkça istenmektedir (Kişisel Verilerin Korunmas1 Kanunu, 2016). 
Tablo 7. Sistem tasarım ve yönetimi (FK7)

\begin{tabular}{|c|c|c|c|c|}
\hline Kurumlar & $\begin{array}{c}\text { Kullanım } \\
\text { Kolaylığı } \\
\text { (4 ister) }\end{array}$ & $\begin{array}{l}\text { Toplam (4 } \\
\text { ister) }\end{array}$ & $\begin{array}{l}\text { Yüzde } \\
\% 100\end{array}$ & $\begin{array}{c}\text { Tüm Kurumların } \\
\text { Oranı }\end{array}$ \\
\hline $\begin{array}{l}\text { Afyonkarahisar Sağlık Bilimleri } \\
\text { Üniversitesi }\end{array}$ & 4 & 4 & $\% 100$ & \multirow{7}{*}{$\% 89,28$} \\
\hline Darıca Belediyesi & 4 & 4 & $\% 100$ & \\
\hline $\begin{array}{l}\text { İzmir Büyükşehir Belediyesi ESHOT } \\
\text { Genel Müdürlüğü }\end{array}$ & 3 & 3 & $\% 75$ & \\
\hline Konya Gıda ve Tarım Üniversitesi & 4 & 4 & $\% 100$ & \\
\hline Sağlık A.Ş. & 3 & 3 & $\% 75$ & \\
\hline Şanlıurfa Büyükşehir Belediyesi & 3 & 3 & $\% 75$ & \\
\hline $\begin{array}{l}\text { Türkiye İhracat ve Kredi Bankası A.Ş. } \\
\text { (Türk Eximbank) }\end{array}$ & 4 & 4 & $\% 100$ & \\
\hline
\end{tabular}

Sistem tasarım ve yönetiminin uygunluğu, kullanım kolaylığıyla ilgili olarak toplam 4 isterde aranmıştır. 2015 öncesi uygunluk oranı, \%47,91'di. 2015 sonrasına bakıldığında bu oranın \%89,28 oranına çıkması sistemin genel itibariyle benimsendiğini ve kullanıldığını göstermektedir.

Tablo 8. Arşiv sisteminin güvenliği (FK8)

\begin{tabular}{|c|c|c|c|c|c|}
\hline Kurumlar & $\begin{array}{c}\text { Sistem } \\
\text { güvenliği } \\
\text { (1 ister) }\end{array}$ & $\begin{array}{c}\text { Bilgi } \\
\text { güvenliği } \\
\text { (3 isteri) }\end{array}$ & $\begin{array}{l}\text { Toplam (4 } \\
\text { ister) }\end{array}$ & $\begin{array}{l}\text { Yüzdelik } \\
\text { Oran }\end{array}$ & $\begin{array}{c}\text { Tüm } \\
\text { Kurumların } \\
\text { Oranı }\end{array}$ \\
\hline $\begin{array}{l}\text { Afyonkarahisar Sağlık } \\
\text { Bilimleri Üniversitesi }\end{array}$ & 1 & 0 & 1 & $\% 25$ & \multirow{7}{*}{$\% 25$} \\
\hline Darıca Belediyesi & 1 & 0 & 1 & $\% 25$ & \\
\hline $\begin{array}{l}\text { İzmir Büyükşehir Belediyesi } \\
\text { ESHOT Genel Müdürlüğü }\end{array}$ & 1 & 0 & 1 & $\% 25$ & \\
\hline $\begin{array}{l}\text { Konya G1da ve Tarım } \\
\text { Üniversitesi }\end{array}$ & 1 & 0 & 1 & $\% 25$ & \\
\hline Sağlık A.Ş. & 1 & 0 & 1 & $\% 25$ & \\
\hline $\begin{array}{l}\text { Şanlıurfa Büyükşehir } \\
\text { Belediyesi }\end{array}$ & 1 & 0 & 1 & $\% 25$ & \\
\hline $\begin{array}{l}\text { Türkiye İhracat ve Kredi } \\
\text { Bankası A.Ş. (Türk Eximbank) }\end{array}$ & 1 & 0 & 1 & $\% 25$ & \\
\hline
\end{tabular}

Arşiv sisteminin güvenliği, sistem güvenliği ve bilgi güvenliği olmak üzere 2 kısımda ve toplam 4 isterde uygunluk aranmıştır. İncelenen kurumların hiçbirinde bilgi güvenliğine ilişkin isterlerin uygunluğuna rastlanmamıştır. TS 13298' in 2015'teki revizyonunda eklenen arşiv sisteminin güvenliğinin uygunluğu \%25 tir. Elde edilen sonuç, kurumların şartnamelerde arşiv sisteminin güvenliğini ilgilendiren isterleri büyük oranda yerine getirmediği görülmektedir. 
Tablo 9. Kurumların TS 13298 fonksiyonel kriterlerine uygunluğu

\begin{tabular}{|c|c|c|c|c|c|c|c|c|c|c|}
\hline Kurumlar & 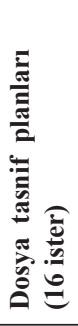 & 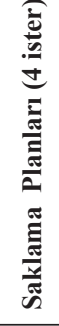 & 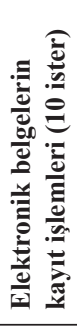 & 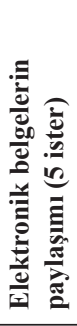 & 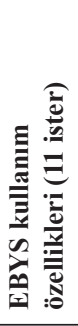 & 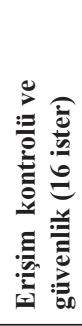 & 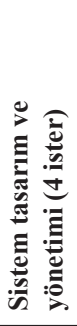 & 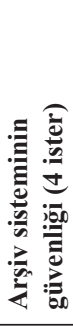 & 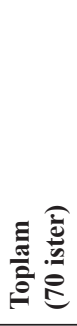 & 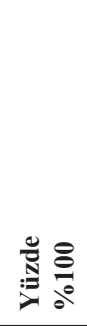 \\
\hline $\begin{array}{l}\text { Afyonkarahisar Sağlık } \\
\text { Bilimleri Üniversitesi }\end{array}$ & $\% 62$ & $\% 0$ & $\% 90$ & $\% 60$ & $\% 100$ & $\% 75$ & $\% 100$ & $\% 25$ & 54 & $\% 77,14$ \\
\hline Darıca Belediyesi & $\% 81$ & $\% 25$ & $\% 100$ & $\% 100$ & $\% 100$ & $\% 81,25$ & $\% 100$ & $\% 25$ & 58 & $\% 82,85$ \\
\hline $\begin{array}{l}\text { İzmir Büyükşehir Belediyesi } \\
\text { ESHOT Genel Müdürlüğü }\end{array}$ & $\% 43$ & $\% 0$ & $\% 60$ & $\% 40$ & $\% 81$ & $\% 50$ & $\% 75$ & $\% 25$ & 36 & $\% 51,42$ \\
\hline $\begin{array}{l}\text { Konya Gıda ve Tarım } \\
\text { Üniversitesi }\end{array}$ & $\% 62$ & $\% 0$ & $\% 90$ & $\% 60$ & $\% 100$ & $\% 75$ & $\% 100$ & $\% 25$ & 50 & $\% 71,42$ \\
\hline Sağlık A.Ş. & $\% 43$ & $\% 0$ & $\% 60$ & $\% 40$ & $\% 81$ & $\% 50$ & $\% 75$ & $\% 25$ & 36 & $\% 51,42$ \\
\hline $\begin{array}{l}\text { Şanlıurfa Büyükşehir } \\
\text { Belediyesi }\end{array}$ & $\% 43$ & $\% 0$ & $\% 60$ & $\% 40$ & $\% 81$ & $\% 50$ & $\% 75$ & $\% 25$ & 36 & $\% 51,42$ \\
\hline $\begin{array}{l}\text { Türkiye İhracat ve Kredi } \\
\text { Bankası A.Ș. (Türk Eximbank) }\end{array}$ & $\% 68$ & $\% 0$ & $\% 60$ & $\% 60$ & $\% 100$ & $\% 75$ & $\% 100$ & $\% 25$ & 51 & $\% 72,85$ \\
\hline
\end{tabular}

Değerlendirilen 7 farklı kurumun TS 13298 fonksiyonel kriterlerine uygunluğu, 8 başlık altında 70 kriterde aranmıştır. 2 üniversite, 4 belediye ve alt kuruluşu ve 1 bankanın uyumluluk oranı, \%50'nin üstündedir. Tabloda dikkat çeken önemli iki nokta görünmektedir. Bunlardan biri, saklama planlarına neredeyse (1 kurum hariç) tüm kurumlar tarafından şartnamelerde yer verilmemiş olmasıdır. İkincisi ise, arşiv sisteminin güvenliğinin yeterince uyumlu olmadığıdır. Sonuçlar, kurumların elektronik ortamdaki arşiv ilke ve uygulamalarını, göz ardı ettiğini göstermektedir. e-Devletteki etkinlik bağlamında değerlendirildiğinde, etkinliğin unsurları görülen şeffaflık, hesap verilebilirlik ve hızlılık kamu kurumlarının evrak kayıt ve belge yönetim sistemlerinin kurulmasına bağlıdır (Keskin, 2011a, s. 558; Keskin, 2011b, s. 1722-1723). Dolayısıyla, arşiv ilke ve uygulamalarının göz ardı edilmesi, e-Devletteki etkinliği artırmada problem olarak görülebilir.

\section{Sonuç ve Tartışma}

Kamu kurumlarındaki EBYS yazılımlarının sağlanması, Kamu İhale Kurumunun Elektronik Kamu Alımları Platformu (EKAP) üzerinden hizmet alımı yöntemiyle yapılmaktadır. EKAP'ta hizmet alımı yapan kurumun hizmet alımına ilişkin dokümanları da bulunmaktadır. $\mathrm{Bu}$ dokümanlardan çalışmanın kapsamında değerlendirilen yazılım hizmetinin teknik ayrıntılarının bulunduğu teknik şartnameler de vardır. Kurumlardaki EBYS yazılımlarının belirli bir standarda göre temin edilmesi, 2008 yılında genelgeyle zorunlu hale gelmiştir. 
Kamu kurumlarındaki EBYS yazılımlarının TS 13298'e uygun olarak hazırlanıp hazırlanmadığını incelemek için, TS 13298 fonksiyonel isterleri ile kurum hizmet alımı teknik şartnamelerinin karşılaştırılmasıyla, EBYS konusunda farkındalık oluşturmaya çalışılmıştır. Daha önce 2015 öncesi yapılan çalışmanın sonuçlarıyla karşılaştırılmak üzere bu farkındalık kapsamında değerlendirilen 7 farklı kamu kurumunun, EBYS yazılımı sağlamada TS 13298'e uygunluğu aranmıştır. Toplam 70 ister kapsamında aranan uyumluluk, sekiz başlık altında ele alınmıştır. Bu sekiz başlık araştırma soruları olarak belirlenmiş ve cevapları oranlı tablolarla gösterilmiştir.

Çalışmanın ilk araştırma sorusunda, kurumların dosya tasnif planlarına uygunluğu incelenmiş ve $\% 58,03$ oranında uyumluluk olduğu görülmüştür. İkinci soruda, saklama planlarına uygunluk oranı \%3,57'dir. Bu sonuç kurumlarda saklama planlarının elektronik ortamda oluşturulmasında problemler olduğunu göstermektedir. Üçüncü araştırma sorusunda, elektronik belgelerin kayıt işlemleri incelenen kurumlar, \% 71,42 oranında uyumluluk sağlamışlardır. Dördüncü soruda ele alınan elektronik belgelerin paylaşımına ilişkin isterler, $\% 57,14$ oranında karşılık bulmuştur. Araştırmanın beşinci sorusunda, EBYS kullanım özellikleri değerlendirilmiş olup \%92,20 uygunluk oranında olduğu görülmüştür. Altıncı soruda, erişim ve güvenlik kontrolü başlığ 1 altında değerlendirilen kurumlar, toplam 16 isterde $\% 65,17$ oranında isterleri karşılamıştır. Yedinci soruda sistem ve tasarım başlığıyla ele alınan kurumlar, \%89,28 oranında 4 istere cevap vermiştir. Bu çalışmanın sekizinci ve son araştırma sorusu olan, arşiv sisteminin güvenliği konusunda, \%25 oranında uyumluluk görülmüştür.

Çalışmanın sekiz araştırma sorusunun sonucunda elde edilen bulguların oranı, 2015 yılı öncesiyle karşılaştığımız da, dosya tasnif planlarının 2015 yılı öncesine oranı \%41,66' dır. 2015 sonrası bu oranın arttığı, ancak bu artışın yüksek oranda olmadığı görülmektedir. Elektronik belgelerin kayıt işlemleri, 2015 yılı öncesi \%30 oranındadır. 2015 sonrası için bu oranın iki kat arttığı görülmektedir. EBYS kullanım özelliklerini değerlendirdiğimizde, 2015 öncesi $\% 55$ oranındadır. 2015 sonrası oranın \%92,20 gibi yüksek bir oranda uyumluluk sağladığ belirlenmiştir. Erişim kontrolü ve güvenlik konusunda, 2015 öncesi oran \%55,55’tir. 2015 sonrası dönemde ise bunun çok fazla artmadığı anlaşılmaktadır. Son olarak sistem tasarım ve yönetimine baktığımızda, 2015 öncesi \%47,91 olan oran, 2015 sonrası neredeyse \%90 oranına yükselmiştir. Saklama planları, elektronik belgelerin paylaşımı ve arşiv sisteminin güvenliğine ilişkin 2015 öncesinde ister söz konusu olmadığı için, 2015 sonrasıyla karşılaştırma yapılmamıştır.

Bu araştırmanın genel değerlendirmesi olarak, kurumlardaki EBYS yazılım uygunluklarının ilgili standardın fonksiyonel kriterlerine göre oranın yükseldiği görülmektedir. Ancak 2015 öncesi ve sonrası için genel olarak belge yönetimi ve arşiv sistemine ilişkin isterlerin göz ardı edilmiş olduğu anlaşılmaktadır. Bu durumun ortaya çıkmasında, teknik şartnamelerin bilgi işlem personeli tarafından veya farklı birimlerin sorumluluk alanlarına göre hazırlanmış 
olabileceği, dolayısıyla arşivcinin veya belge yöneticisinin teknik şartname hazırlık aşamasında yer almadığı ihtimalini ortaya koymaktadır. Bu durum; arşivcinin ve belge yöneticisinin projede yer almadığı, söz konusu kurumlarda istihdam edilmediği veya istihdam edilmiş olsa bile önemsenmediği anlamına gelebilecek bir izlenim vermektedir. Bir başka ihtimal de arşivcinin veya belge yöneticisinin kurumlardaki görünürlüklerinin yeterli olmamasıdır. Araştırmada bir diğer genel değerlendirme sonucu ise kriterleri yeterince sağlamayan bazı kurumların, her yıl EBYS yazılımının bakım ve destek hizmet alımı ihalesine çıkmış olmalarıdır. Bunun verilerle ortaya konması, ayrı bir araştırmanın konusu olarak görülebilir.

Hakem Değerlendirmesi: Dış bağımsız.

Çıkar Çatışması: Yazar çıkar çatışması bildirmemiştir.

Finansal Destek: Yazar bu çalışma için finansal destek almadığını beyan etmiştir.

Peer-review: Externally peer-reviewed.

Conflict of Interest: The author has no conflict of interest to declare.

Grant Support: The author declared that this study has received no financial support.

\section{Kaynakça/References}

Afyonkarahisar Sağlık Bilimleri Üniversitesi. (2018). EBYS yazılımı teknik şartnamesi (İhale Kayıt No: 2018/613757). Erişim adresi: https:/ekap.kik.gov.tr/EKAP/Ortak/IhaleArama/index.html

Aksoy, M. ve Şimşek, M. (2010). En son değişikliklerle (Kamu İhale Kurulu kararları ışığında) kamu alımları ihale süreci (mal ve hizmet alımları ile yapım işleri). Ankara: Maliye Bakanlığı Strateji Geliştirme Başkanlığı Yayınları.

Atuğ, M. ve Taytak, M. (2018). Kamu satın alımları kapsamında doğrudan temin uygulamalarının değerlendirilmesi ve bir vaka analizi. Sayıştay Dergisi, 110, 91-123.

Çiçek, N. (2012, 21-23 Kasım). Kamu kurumlarında yürütülen elektronik belge yönetimi ve sayısallaştırma uygulamalarında karşılaşılan teknik ve idari problemler: İstanbul Büyükşehir Belediyesi, ÇAYKUR ve Esenler Belediyesinin ihale teknik şartnameleri üzerine karşılaştırmalı bir inceleme. M. Yıldırır ve S. Kadığlu (Yay. Haz.), Osmanlı Coğrafyası Kültürel Arşiv Mirasının Yönetimi ve Tapu Arşivlerinin Rolü Uluslararası Kongresi (s. 857-873) içinde. Ankara: Tapu Kadastro Genel Müdürlüğü.

Darıca Belediyesi. (2017). Süreç bazlı web tabanlı yönetim bilgi sistemi yazılım modülleri ve elektronik belge yönetim sistemi hizmet alımı işi teknik şartnamesi (İhale Kayıt No: 2017/396242). Erişim adresi: https:// ekap.kik.gov.tr/EKAP/Ortak/IhaleArama/index.html

Güler, C. (2018). Kamu kurumlarında elektronik belge yönetimi uygulamalarında karşılaşılan problemler: Teknik şartnamelerin incelenmesi. Arşiv Dünyası, 21, 1-21.

İzmir Büyükşehir Belediyesi ESHOT Genel Müdürlüğü. (2017). Elektronik belge yönetim sistemi (EBYS) teknik şartnamesi (İhale Kayıt No: 2017/216516). Erişim adresi: https://ekap.kik.gov.tr/EKAP/Ortak/ IhaleArama/index.html 
Kamu İhale Kanunu. (2002, 22 Ocak). Resmi Gazete (Sayı: 24648). Erişim adresi: http://www.mevzuat.gov. tr/MevzuatMetin/1.5.4734.pdf

Kamu İhale Sözleşmeleri Kanunu. (2002, 22 Ocak). Resmi Gazete (Sayı: 24648). Erişim adresi: https://www. mevzuat.gov.tr/MevzuatMetin/1.5.4735.pdf

Kamu İhale Tebliği. (2018, 19 Ocak). Resmi Gazete (Say1: 30306). https://www.resmigazete.gov.tr/ eskiler/2018/01/20180119-6.htm

Kamu İhale Tebliği. (2019, 25 Ocak). Resmi Gazete (Sayı: 30666). Erişim adresi: https://www.resmigazete. gov.tr/eskiler/2019/01/20190125-17.htm

Kamu İhale Tebliği. (2020, 29 Ocak), Resmi Gazete (Sayı: 31023). Erişim adresi: https://www.resmigazete. gov.tr/eskiler/2020/01/20200129-6.htm

Keskin, İ. (2011a). Şeffaflaşma aracı olarak bilgi edinme ve araştırma hakkı. İstanbul Üniversitesi Sosyoloji Dergisi, 3(22), 557-572.

Keskin, İ. (2011b). "E-devlet uygulamalarının kamu yönetiminde şeffaflaşmaya etkisi”, 9th international conference on knowledge, economy \& management proceedings içinde (1715-1728). Zeki Parlak, İbrahim Güran Yumuşak (Eds.), Sarajevo: International University of Sarajevo.

Kişisel Verilerin Korunması Kanunu. (2016, 24 Mart). Resmi Gazete (Sayı: 29677). Erişim adresi: https:// www.resmigazete.gov.tr/eskiler/2016/04/20160407-8.pdf

Konya Gıda ve Tarım Üniversitesi. (2017). Elektronik belge yönetim sistemi şartnamesi (İhale Kayıt No: y.). Erişim adresi: https://ekap.kik.gov.tr/EKAP/Ortak/IhaleArama/index.html

Sağlık A.Ş. (2017). Elektronik belge yönetim sistemi (EBYS) alımı işi teknik şartnamesi (İhale Kayıt No: 2017/571190). Erişim adresi: https:/ekap.kik.gov.tr/EKAP/Ortak/IhaleArama/index.html

Şanlıurfa Büyükşehir Belediyesi. (2016). Elektronik belge yönetim sistemi (EBYS) teknik şartnamesi (İhale Kayıt No: 2016/19671). Erişim adresi: https://ekap.kik.gov.tr/EKAP/Ortak/IhaleArama/index.html

Türk Standartları Enstitüsü. (2015). Elektronik belge ve arşiv yönetimi sistemi (TS 13298). Ankara: TSE

Türkiye İhracat ve Kredi Bankası A.Ş. (Türk Eximbank). (2018). Elektronik belge yönetim sistemi (EBYS) uygulaması lisans, geliştirme, danışmanlık, kurulum, bakım ve destek hizmeti alımı teknik şartnamesi (İhale Kayıt No: 2018/15724). Erişim adresi: Erişim adresi: https://ekap.kik.gov.tr/EKAP/Ortak/IhaleArama/ index.html

Umut, G. ve Külcü, Ö. (2014). Elektronik belge yönetimi uygulamalarında karşılaşılan sorunların analizi ve çözüm önerileri: Kalkınma Bakanlığı örneği. Bilgi Dünyası, 15(1), 102-124.

Yalçınkaya, B. (2015). Elektronik belge yönetimi (EBY) uygulamalarında başarıyı olumsuz etkileyen risk unsurları. Bilgi ve Belge Araştırmaları Dergisi, 4, 20-40. 